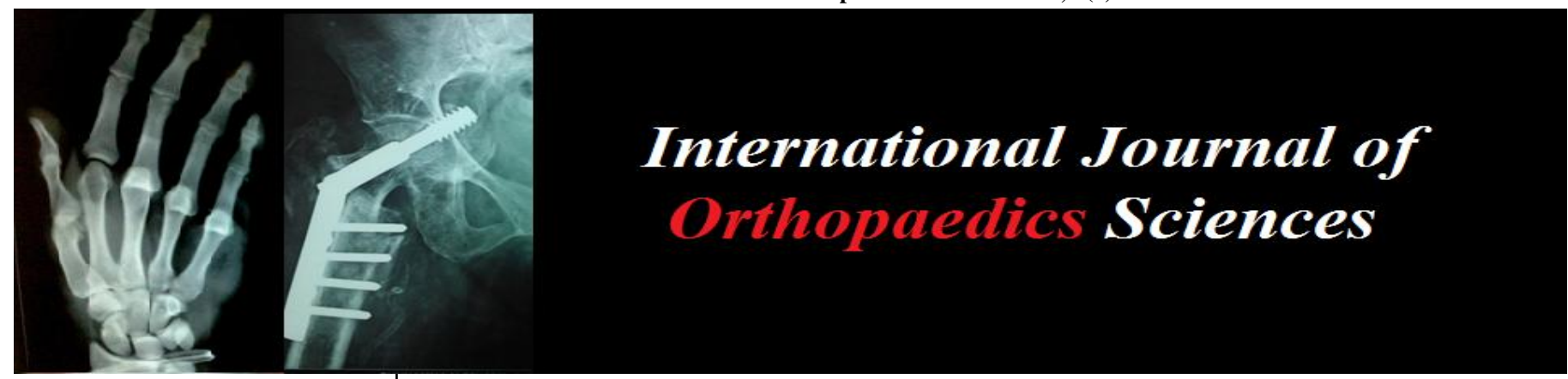

ISSN: $2395-1958$

IJOS 2017; 3(4): 927-930

(C) 2017 IJOS

www.orthopaper.com

Received: 28-10-2017

Accepted: 19-11-2017

Dr. Mahendra Kumar KL

Associate Professor, Department of Orthopedics, Mims, Mandya,

Karnataka, India

Dr. Manjappa CN

Professor, Department of

Orthopedics, MIMS, Mandya,

Karnataka, India
Correspondence

Dr. Manjappa CN

Professor, Department Of

Orthopedics, MIMS, Mandya,

Karnataka, India

\section{Surgical management of patients with tibial plateau fracture using minimally invasive technique with locking compression plate retrospective study}

\section{Dr. Mahendra Kumar KL and Dr. Manjappa CN}

DOI: $\underline{\text { https://doi.org/10.22271/ortho.2017.v3.i4m.127 }}$

\section{Abstract}

Introduction: The following study was conducted to identify the short term clinical and radiological results particularly early complications and healing rate of tibial plateau fracture treated with LCP using MIPPO.

Materials and Methods: The study was conducted in patients treated for tibial plateau fracture (type 1 to 4 schatzker's classification) at Mandya Institute of Medical Sciences, Mandya from month of Nov 2015 to Oct 2017. Forty tibial plateau fracture patients were fixed with LCP using MIPPO technique of schatzker's type 1 to 4 in this study. Patients' age ranged from 18 to 65 years.

Results: The sample consisted forty patients, 31 were males and 09 females. The patients' ages ranged from 18-65 years with mean age of 41.5 years. The causes of fractures were motor vehicle accident in 26 patients, self-fall in 11 and fall from height in 03 patients. 26 fractures involved the right side and 14 involved the left. The average hospitalization was 15 days with a range of 10 to 20 days. The average number of days from injury to surgery was 5 days with a range of 02 to 07 days. Functional outcome was rated as per NEER'S RATING SCORE, we got excellent results in 14 cases, good in 15, fair in 08 and poor in 03 patients.

Conclusion: The tibial plateau fracture fixation with LCP using MIPPO technique provides accurate positioning and fixation. We recommend use of this implant in Schatzker's Type 1, 2, 3, 4 and osteoporotic fractures with satisfactory results. In our study, we found excellent results in type 1-4 Schatzker's and osteoporotic fractures, however, long term studies are needed to prove definitively acceptable outcomes so that this technique can become part in the armamentarium of the orthopedic trauma surgeon.

Keywords: Tibial plateau fracture, MIPPO, LCP, Neer's rating score

\section{Introduction}

Road traffic accidents are one of the major cause of death in developed as well as developing countries leading to increased orthopaedic related morbidity and mortality. In the recent past the principles of fracture management have been changed from just mechanical fixation to the concept of considering the biological aspects of the injury because biological osteosynthesis is characterized by the preservation of bone and soft tissue vascularity rather than absolute fixation ${ }^{[1,2]}$. The proximal tibia is involved in body weight transmission through the knee joint and leg, it plays a vital role in the knee joint function and stability. The majority of tibial plateau fractures are secondary to high velocity road traffic accidents and fall from height where fractures result from direct axial compression ${ }^{[3]}$ and extra-articular fractures more commonly secondary to direct bending forces to the metadiaphyseal region of upper leg. Older patients with osteopenic bone are more likely to sustain depression type fracture because their subchondral bone is less likely to resist axial directed load ${ }^{[4]}$.

The aim of surgical treatment in proximal tibial fractures is aimed to restore and preserve normal knee function, which can be achieved by anatomical restoration of articular surfaces, maintaining mechanical axis, restoring stability of ligaments and preserving a functional pain free range of movements of knee. The incidence of mal-union, non-union and infections are relatively high in many reported series, causing significant long term disability. Recently more attention has been paid to the condition of soft tissue envelope. Soft tissue friendly approaches and minimally invasive techniques have improved the outcome. 
With the better understanding of fracture healing biology and biomechanics of fracture fixation and healing, there is evolution of new concept of fracture fixation with fixed angular stable plate, (LCP) and minimally invasive surgical techniques. The trend of treatment is towards biological fixation, which can be accomplished by LCP and MIPPO technique which is widely accepted ${ }^{[5]}$.

Locking compression plate offers potential biomechanical advantage over other methods by better distribution of forces along the axis of bone, can be inserted with minimal soft tissue stripping using minimally invasive percutaneous plate osteosynthesis (MIPPO), substantially reduces failure of fixation in osteoporotic bones, better preservation of blood supply to the bone as a locked plating does not rely on plate bone compression, provides stable fixation by creating a fixed angle construct and angular stability and allows early mobilization ${ }^{[6]}$.

The main objective of the study was to assess the functional outcome using Neer's rating score and the data was obtained from a retrospective review of 40 consecutive patients who presented with tibial plateau fracture and surgically managed with locking compression plate by MIPPO.

\section{Materials and methods}

This was a retrospective study conducted at department of orthopedics, Mandya Institute of Medical Sciences. The patients who attended the orthopedic department of Mandya Institute of Medical Sciences with tibial plateau fracture schatzker's type 1 to 4 and with their complete data during November 2015 to October 2017 were included in this study. Patients with incomplete data and schatzker's type $5 \& 6$ were excluded from the study. Type $2 \& 3$ in schatzker's classification elevation of fracture depression was done by creating a cortical window using a small osteotome followed by LCP-MIPPO. Personal data and pattern of injuries who underwent the tibial plateau LCP-MIPPO operative procedure were extracted from the case records and OT register. Data extraction was manually done by reviewing each case file. Data collected was analyzed using simple statistical method of percentages and functional outcome was rated using Neer's scoring systems.

\section{Results}

This is a study of 40 cases of tibial plateau fracture in adults and elderly treated by proximal tibial locking compression plate (LCP) using MIPPO during the study period. All cases were available for follow up. Out of these, the maximum were in the age group of 35-60 years $(n=33,82.5 \%)$. There were 31 males $(77.5 \%)$ and 09 females $(22.5 \%)$. Motor vehicle accidents were the most common cause of fracture proximal tibia responsible for $65 \%(n=26)$, self-fall for $27.5 \%(n=11)$ and fall from height for $7.5 \%(n=3)$ of cases.

In our study, open fractures accounted for $7.5 \%(n=3)$ and remaining being closed fractures $92.5 \%(\mathrm{n}=37)$ and $65 \%$ $(n=26)$ involved right tibia and $35 \%(n=14)$ involved left tibia. According to schatzker's classification we had $22.5 \%$ $(n=9), 45 \%(n=18), 12.5 \%(n=5), 20 \%(n=8)$ in type $1,2,3 \&$ 4 respectively. Type 5 and 6 in schatzker's classification were excluded from the study. Study revealed $7.5 \%(n=3)$ cases with poor knee flexion of $<90^{\circ}, 55 \%(n=22)$ with flexion range of $91-119^{\circ}$ and $37.5 \% \quad(n=15)$ with good flexion of $>120^{\circ}$. Two cases had deep infection which required wound debridement and subsequent implant removal, $7.5 \%(n=3)$ had knee stiffness and $17.5 \%(n=7)$ had knee pain.

The functional outcome was assessed according to Neer's rating score and we had excellent results in $35 \%(n=14)$, good in $37.5 \%(n=15)$, fair in $20 \%(n=8)$ and poor in $7.5 \%(n=3)$.

Table 1

\begin{tabular}{|c|c|c|}
\hline Schatzker's classification & No. of cases & Percentage \\
\hline Type 1 & 09 & 22.5 \\
\hline Type 2 & 18 & 45 \\
\hline Type 3 & 05 & 12.5 \\
\hline Type 4 & 08 & 20 \\
\hline Type 5 & 00 & 00 \\
\hline Type 6 & 00 & 00 \\
\hline
\end{tabular}

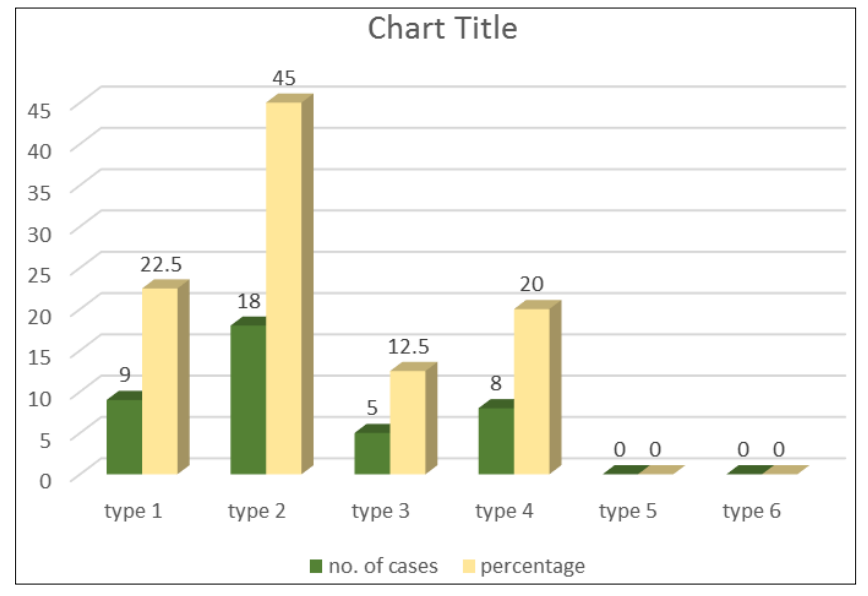

Table 2: Complications

\begin{tabular}{|c|c|c|}
\hline Complications & No. of cases & Percentage \\
\hline Stiffness & 03 & $7.5 \%$ \\
\hline Infection & 02 & $5 \%$ \\
\hline Knee pain & 07 & $17.5 \%$ \\
\hline Implant removal \& debridement & 02 & $5 \%$ \\
\hline Skin necrosis & 00 & 00 \\
\hline Implant failure & 00 & 00 \\
\hline Bone grafting & 00 & 00 \\
\hline
\end{tabular}

Table 3: Neer's rating score

\begin{tabular}{|c|c|c|}
\hline Neer's rating score & No. of cases & Percentage \\
\hline Excellent & 14 & 35 \\
\hline Good & 15 & 37.5 \\
\hline Fair & 08 & 20 \\
\hline Poor & 03 & 7.5 \\
\hline
\end{tabular}

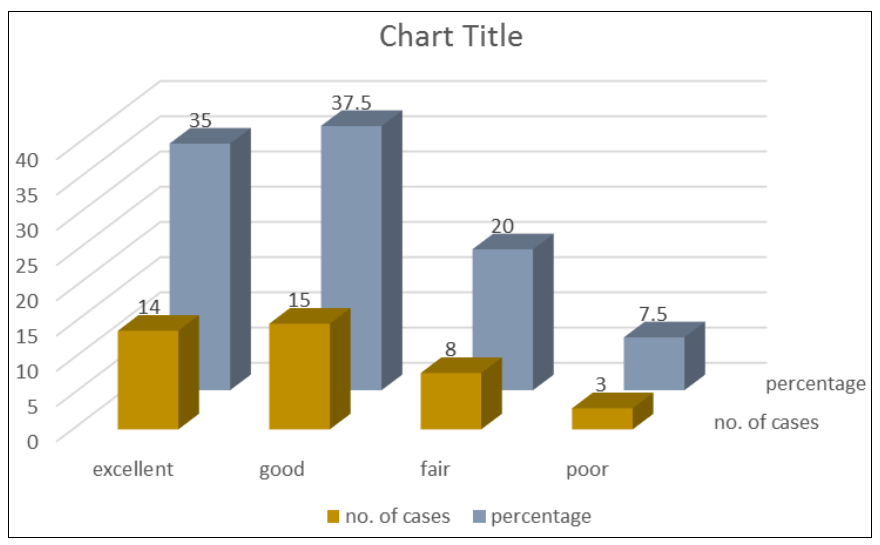

\section{Discussion}

With the increase in RTA there is not only increase in incidence of proximal tibial fracture but also complexity of fracture has changed due to high velocity impact. Because the knee joint is a weight bearing joint, fractures around are of utmost importance as they result in increased orthopedic 
mortality and morbidity. Treatment modalities have been continuously changing in quest of better results. An orthopedic surgeon is challenged by fracture comminution, instability, displacement and extensive soft tissue injures. As with any other fracture the treatment goals are to restore congruence of joint, limb alignment, stability of knee joint, fracture union and soft tissue healing as well as to restore functional range of knee movements.

However with better understanding of biomechanics of fracture healing, treatment aims at restoring the biological osteosynthesis which is characterized by the preservation of bone and soft tissue vascularity and relative rather than absolute fixation ${ }^{[2]}$. Of late more attention has been paid to soft tissue friendly approaches achieved by minimally invasive techniques. The use of LCP in the tibial fractures has been shown more advantageous compared with the conventional techniques. In this study, we made an attempt to study the functional outcome using Neer's rating score.

This study comprised of forty patients with Tibial plateau Fractures who were treated with Locking Compression plate by minimally invasive technique. Overall final outcome was assessed in terms of regaining the lost knee function using NEER'S Score.

The patients with fracture in our study occurred between the ages of 18 to 65 years with maximum incidence involving the productive age group of 35-60 years $(82.5 \%)$. This was in accordance with studies by Cole PA et al. ${ }^{[7]}$ Ricci et al. ${ }^{[8]}$ and Stannard et al. ${ }^{[9]}$ who found majority of patients age with an average of 45, 53 and 38 years respectively. Among modes of injury road traffic accidents are the most common $(65 \%)$ with more $(57.5 \%)$ fractures on right side. These are comparable to the studies made by Dendrinos et al. ${ }^{[10]}$ Barei et al. ${ }^{[11]}$ and Patil et al. ${ }^{[12]}$

According to literature type II fractures are the most common, in our study group also we had higher number of type 2 followed by type 1 and 4 . Type 5 and 6 schaztker's fracture types required open reduction and fixation with dual plating and hence they were excluded from the study group. In this present study we preferred Schatzker Classification because it is simple, uncomplicated and no special $\mathrm{x}$-rays are required. Its practical utility to carry out treatment and prognosis has got an upper hand.

Cole et al. ${ }^{[13]}$ reported the results of 42 consecutive tibial plateau fractures with $91 \%$ union, $9 \%$ malalignment, and $4 \%$ infection rate. Krupp et al. ${ }^{[14]}$ found that locked plating was associated with a decreased time to union, decreased incidence of articular malunion, decreased knee stiffness, and decreased overall complications. In our study, complications were knee pain, stiffness and infection similar to above studies. For patients with stiffness again physiotherapy was started with active and passive knee exercises, CPM and wax therapy.

Lee et al. ${ }^{[15]}$ reported good to excellent results by surgical means of less invasive stabilization system treatment. Feng et al [16] reported good results when fixed with LCP in comparison with dynamic compression plate (DCP) with an additional benefit of minimally invasive surgery. Kim et al. ${ }^{[17]}$ reported good results with MIPPO technique in treatment of open proximal tibial fractures with adequate soft tissue coverage. With the better understanding of fracture healing biology and biomechanics of fracture fixation and healing, there is evolution of new concept of fracture fixation with fixed angular stable plate, (LCP) and minimally invasive surgical techniques. The trend of treatment is towards biological fixation, which can be accomplished by LCP and
MIPPO technique which is widely accepted ${ }^{[5]}$. Which supports our study goal.

An average of $105^{\circ}$ knee joint range of motion was achieved. Soft tissue damage, intraarticular extension, severity of communition and physiotherapy determined knee range of motion. Both Cole PA et al. ${ }^{[7]}$ and Egol et al. ${ }^{[18]}$ reported similar range of movement results when using locked plate for these fractures (range 0 to $122^{\circ}$ and 0 to $109^{\circ}$ respectively).

\section{Conclusion}

Locking compression plate is a good fixation system for tibial plateau fractures which provides angular stability by its triangular reconstruction principle and thus helps in early mobilization. In contrast to other studies where LCP was used, this study used the plate through minimally invasive technique where soft tissue damage is considerably less, since periosteal stripping and soft tissue exposure can be kept to a minimum.

To conclude Locking Compression Plate is an optimal tool for tibial plateau fractures. Minimally invasive technique under the guidance of image intensifier provides better plate placement, significantly less periosteal stripping and soft tissue exposure. However careful understanding of its basic principles, identification of appropriate fracture patterns for use of LCP is essential to avoid complications. However a more comprehensive study with longer follow up periods is essential to throw more light into the advantages, complications and possible disadvantages of the use of Locking Compression Plate with special attention to the long term outcomes.

\section{References}

1. Schatzker J, Brudnicki J. The evolution of AO/ASIF views on fracture treatment. Chir Narzadow Ruchu Orthop Pol. 2006; 71:275-279.

2. Zeng B. Minimally invasive surgery in fracture management. Chin Med J. 2008; 121(15):1349-1351.

3. Koval KJ, Hulfut DL. Tibial plateau fracture: evaluation and treatment. J Am Acad Orthop Surg. 1995; 3(2):8694.

4. Biyani A, Reddy NS, Chaudhary et al. The results of surgical management of displaced tibial plateau fracture in the elderly. Injury. 1995; 26(5):291-297.

5. Stoffel Dietaru K. Biomechanical testing of the LCP how can stability in locked internal fixator be controlled? Injury. 2003; 34(2):B11-9.

6. Kenneth Egol A, Kenneth Koval J. In: Fractures of proximal tibia: chapter 50, Rockwood and Green's Fractures in Adults, 6th edition, Lippincott Williams and Wilkins, 2006, 2.

7. Cole PA, Zlowodzki M, Kergor J. Treatment of proximal tibia fracture using the Less Invasive Stabilization System. Surgical experience and early clinical results in 77 fractures. J Orthop. 2004; 18:528-35.

8. Ricci WM, Rudzki JR, Borrelli J Jr. Treatment of complex proximal tibial fracture with the less invasive skeletal stabilization system. J Orthop Trauma. 2004; 18:521-7.

9. Stannard JP, Wilson TC, Volgas DA, Alonso JE. Fracture stabilization of proximal tibial fracture with the proximal LISS: early experience in Birmingham, Alabama (USA). Injury. 2003; 34:A30-5.

10. Dendrinos GK, Kontos S, Katsenis D, Dalas K. Treatment of high-energy tibial plateau fracture by the 
llizarov circular external tibial plateau fixator. JBJS 1996; 78(B):710-717.

11. Barei DP, Nork SE, Mills WJ, Coles CP, Henley MB, Benirschke SK. Functional Outcomes of Severe Bicondylar Tibial Plateau Fractures Treated with Dual Incisions and Medial and Lateral Plates. JBJS. 2006; 88(A):1713-1721.

12. Patil DG, Ghosh S, Chaudhuri A, Datta S, De C, Sanyal P. Comparative study of fixation of proximal tibial fractures by nonlocking buttress versus locking compression plate. Saudi J Sports Med. 2015; 15:142147.

13. Cole Peter MD, Zlowodzke Micheal MD, Kregor Philip JMD. Treatment of proximal tibial fractures using the Less Invasive Stabilisation System: Surgical Experience And Early Clinical results in 77 fractures. Journal of orthopaedic trauma. 2004; 18(8):528-535.

14. Krupp RJ, Malkani AL, Roberts CS, Seligson D, Craford $\mathrm{CH}$, Smith LBS. Treatment of Bicondylar Tibia Plateau Fractures Using Locked Plating Versus External Fixation. Orthop. 2009; 32(8):559.

15. Lee JA, Papadakis SA, Moon C, Zalavras CG. Tibial plateau fractures treated with the less invasive stabilisation system. Int Orthop. 2007; 31:415-418.

16. Feng W, Fu L, Liu J, Qi X, Li D, Yang C. Biomechanical evaluation of various fixation methods for proximal extra-articular tibial fractures. J Surg Res. 2012; 178:722727.

17. Kim JW, Oh CW, Jung WJ, Kim JS. Minimally invasive plate osteosynthesis for open fractures of the proximal tibia. Clin Orthop Surg, 2012; 4:313-320.

18. Egol KA, Su E, Tejwani NC, Sims SH, Kummer FJ, Koval KJ. Treamtent of complex tibial plateau fractures using the less invasive stabilization system plate. J trauma. 2004; 57:340-6. 